\title{
Vertical Change in Extinction and Atmospheric Particle Size in the Boundary Layers over Beijing: Balloon-borne Measurement
}

\author{
Bin Chen ${ }^{1,2)}$, Guang-Yu Shi ${ }^{1)}$, Maromu Yamada ${ }^{3)}$, Dai-Zhou Zhang ${ }^{4)}$, \\ Masahiko Hayashi ${ }^{5)}$ and Yasunobu Iwasaka ${ }^{6) *}$ \\ ${ }^{1)}$ State Key Laboratory of Numerical Modeling for Atmospheric Sciences and Geophysical Fluid Dynamics (LASG), \\ Institute of Atmospheric Physics, Chinese Academy of Sciences, Beijing 100029, China \\ ${ }^{2)}$ Graduate School of Chinese Academy of Sciences, Beijing 10039, China \\ ${ }^{3)}$ Center for Innovation, Kanazawa University, Kakuma-machi, Kanazawa 920-1192, Japan \\ ${ }^{4)}$ Faculty of Environmental and Symbiotic Sciences, Prefectural University of Kumamoto, 3-1-100 Tsukide, \\ Kumamoto 862-8502, Japan \\ ${ }^{5)}$ Department of Earth System Science, Graduate School of Science, Fukuoka University, 8-19-1 Nanakuma, Jonan-ku, \\ Fukuoka 814-0180, Japan \\ ${ }^{6)}$ Frontier Science Organization, Kanazawa University, Kakuma-machi, Kanazawa 920-1192, Japan
}

*Corresponding author. Tel: +81-76-234-4645, E-mail: kosa@staff.kanazawa-u.ac.jp

\begin{abstract}
Aerosol size and number concentration were observed in the atmospheric boundary layer over Beijing (from near the ground to $1,200 \mathrm{~m}$ ) on March 15 (a clear day) and 16 (a dusty day), 2005. The results were further compared with lidar measurements in order to understand the dependency of extinction on the particle size distribution and their vertical changes. The boundary layer atmosphere was composed of several sub-layers, and a dry air layer appeared between 400 and $1,000 \mathrm{~m}$ under the influence of dust event. In this dry air layer, the concentration of the fine-mode particles (diameter smaller than $1.0 \mu \mathrm{m}$ ) was slightly lower than the value on the clear day, while the concentration of coarse-mode particles (diameter larger than $1.0 \mu \mathrm{m}$ ) was remarkably higher than that on the clear day. This situation was attributed to the inflow of an air mass containing large amounts of Asian dust particles and a smaller amount of fine-mode particles.

The results strongly suggest that the fine-mode particles affect light extinction even in the dusty atmosphere. However, quantitatively the relation between extinction and particle concentration is not satisfied under the dusty atmospheric conditions since laser beam attenuates in the atmosphere with high concentration of particles. Laser beam attenuation effect becomes larger in the relation between extinction and coarse particle content comparing the relation between extinction and fine particle content. To clarify this problem technically, future in situ measure-
\end{abstract}

ments such as balloon-borne lidar are suggested. Here extinction was measured at $532 \mathrm{~nm}$ wavelength. Measurements of extinction at other wavelengths are desired in the future.

Key words: Extinction, Vertical distribution of aerosol, Particle size, Boundary layer, Visibility

\section{INTRODUCTION}

Atmospheric aerosols play an important role in climate change by affecting global cloud albedo, radiative transfer, ozone chemistry, acid rain, and visibility (Jacobson et al., 2001; Seinfeld et al., 1998; Charlson et al., 1992). They also have an important and direct effect on the atmospheric environment and human health (Chan et al., 1997). Increases in the number concentration of aerosol particles, especially the fine particulate matter (particles with diameter smaller than $2.5 \mu \mathrm{m}: \mathrm{PM}_{2.5}$ ), may also have significant health effects (Donaldson et al., 1998; Dockery et al., 1994), reduce visibility, and concentrate large amounts of poisonous compounds in the air (An et al., 2000; Prospero et al., 1999). Such harmful effects have understandably caused widespread public concern (Zhang et al., 2003). Indeed, particulate matter is one of the key pollutant types in most of the big cities in China (Wang et al., 2000).

Reduced visibility has become a severe issue in many large cities of the world and can cause inconveniences in daily life disturbing traffic and transpor- 


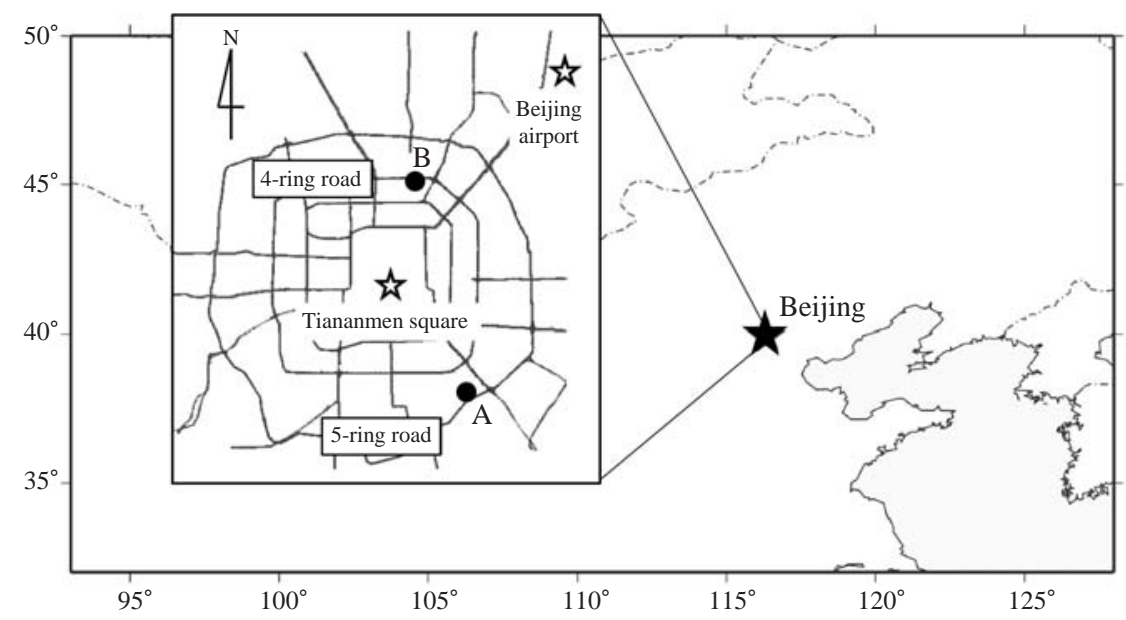

Fig. 1. Observation sites. (A) Base of the atmospheric observation; (B) China-Japan Friendship Environmental Protection Centre.

tation including delay of flights. Many studies have investigated issues of reduced visibility and particulate matter (Wang et al., 2006; Song et al., 2003; Yan et al., 2003; Chan et al., 1999; Baik et al., 1996; Larson et al., 1989).

These studies have mostly been based on ground observations and few measurements have investigated the particulate characteristics and visibility in the free atmosphere or boundary mixing layer over urban regions of China. Knowledge of free atmospheric particulate content and its effect on slant visibility is essential to control safely aviation system considering that activities of big cities including Beijing city are strongly depending on air transportation. Beijing, which has approximately 14.4 million inhabitants, has been experiencing rapid economic growth and urbanization for decades, and consequently faces many problems due to pollution. In addition, previous studies have focused on monitoring $\mathrm{PM}_{10}$ and $\mathrm{PM}_{2.5}$ particles, without clarifying size dependences.

The results described here is the first case study discussing the vertical change in aerosol size/number concentration and extinction (at wavelength $=532 \mathrm{~nm}$ ) in the boundary layer over Beijing, China, on the basis of the measurement with balloon-borne optical particle counters and lidar.

\section{MEASUREMENTS AND METHODS}

\subsection{Observation Sites}

Tethered-balloon measurements were performed at the Atmospheric Observing Experimental Base of Institute of Atmospheric Physics $\left(39.82^{\circ} \mathrm{N}, 116.47^{\circ} \mathrm{E}\right)$, close to the south $5^{\text {th }}$ Ring Road in Beijing, south-east of the central part of the city (Matsuki et al., 2005;

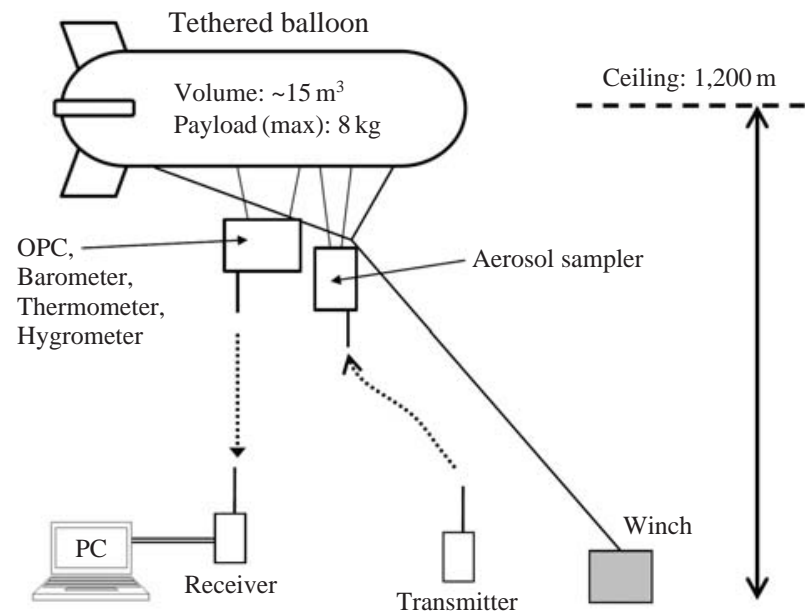

Fig. 2. Balloon train.

Fig. 1). Lidar measurements were performed at the China-Japan Friendship Environmental Protection Centre $\left(39.98^{\circ} \mathrm{N}, 116.42^{\circ} \mathrm{E}\right)$ which is near the northcentral part of the $4^{\text {th }}$ Ring Road and locates $18 \mathrm{~km}$ north of the tethered-balloon site. The distance between the two observation sites was about $10 \mathrm{~km}$. This difference, as described later, can reasonably be neglected considering the atmospheric structures of the planetary boundary layer observed here.

\section{2 Instrumentation and Measurements}

The tethered-balloon (TB) observation system is similar to that described by Matsuki et al. (2005), so we describe the specifications of the system only briefly here. Fig. 2 shows the balloon train used. A barometer was mounted on the balloon to measure the atmospheric pressure, which we used to calculate alti- 
tude. The balloon system could reach an altitude of $1,200 \mathrm{~m}$ above the ground within 30-40 minutes. It was therefore possible to monitor the changes in aerosols at a time resolution of about 1 hour. The size and number concentration of the atmospheric aerosols were observed in 20-second intervals with an optical particle counter (OPC), which sized particles at diameters of $0.3,0.5,1.0,2.0$, and $5.0 \mu \mathrm{m}$ (Yamashita et al., 2003). A detailed description of the counter was given by Hayashi et al. (1998). Vertical profiles of the number concentration of particles, temperature, relative humidity, and air pressure in the same air mass were obtained by balloon-borne measurements at high vertical resolution (about $0.5 \mathrm{~m}$, with resolution dependent on the sounding speed). Table 1 lists the observation time and meteorological conditions near the surface at the balloon site.

Detailed specifications of the polarization lidar, which was installed at the China-Japan Friendship Environmental Protection Centre, can be found in Shimizu et al. (2004). The lidar measurements were made using backscattering light from atmospheric particles at $532 \mathrm{~nm}$ wavelength (second harmonic wavelength of Nd: YAG laser). Scattering light received by a telescope with a diameter of $20 \mathrm{~cm}$, and de- tected with photomultiplier tubes. A detailed description of the lidar was given by Sugimoto et al. (2003).

\section{RESULTS AND DISCUSSION}

\section{1 The Relationship between Visibility and Extinction}

The relationship between visibility and atmospheric extinction is expressed as (Koschmieder et al., 1924)

$$
L_{v}=-\ln 0.02 / b=3.912 / b_{p}
$$

where $L_{v}$ is the visibility in kilometres and $b$ is the atmospheric extinction per kilometre. This formulation is widely used in the routine measurement of the meteorological observatory in the world and regarded as one of the global standards.

The atmospheric extinction can be broken into three parts: $b=b_{r}+b_{a}+b_{p}$, where $b_{r}$ is the molecular Rayleigh scattering, $b_{a}$ is the gaseous absorption, and $b_{p}$ is the extinction due to aerosols. Under standard conditions (sea-surface temperature $15^{\circ} \mathrm{C}$, air pressure 1013.25 $\mathrm{hPa}$, air density $1.2250 \mathrm{~kg} / \mathrm{m}^{3}$ ), the value of Rayleigh scattering is $0.013 \mathrm{~km}^{-1}$ (Peundorf et al., 1957). Some atmospheric gas species, especially $\mathrm{NO}_{2}$, may have ab-

Table 1. Surface meteorological records and observing time.

\begin{tabular}{lccccccc}
\hline \multirow{2}{*}{ Time } & \multicolumn{7}{c}{ Items } \\
\cline { 2 - 8 } & $\begin{array}{c}\text { Temperature } \\
\left({ }^{\circ} \mathrm{C}\right)\end{array}$ & $\begin{array}{c}\text { Relative } \\
\text { humidity }(\%)\end{array}$ & $\begin{array}{c}\text { Wind } \\
\text { speed }(\mathrm{m} / \mathrm{s})\end{array}$ & $\begin{array}{c}\text { Wind } \\
\text { direction }(\mathrm{deg} .)\end{array}$ & $\begin{array}{c}\text { Cloud }(0-10) \\
(\text { Total/Low })\end{array}$ & $\begin{array}{c}\text { Visibility } \\
(\mathrm{km})\end{array}$ & $\begin{array}{c}\text { Weather } \\
\text { records }\end{array}$ \\
\hline $\begin{array}{l}\text { 2005/03/15 } \\
\text { 16:30-18:30 }\end{array}$ & 14.1 & 18 & 2.5 & $\mathrm{SSW}$ & $0 / 0$ & 20.0 & Clear \\
$\begin{array}{l}\text { 2005/03/16 } \\
16: 30-18: 30\end{array}$ & 14.0 & 27 & 1.6 & $\mathrm{SSW}$ & $10 / 0$ & 9.0 & Smoke screen \\
\hline
\end{tabular}
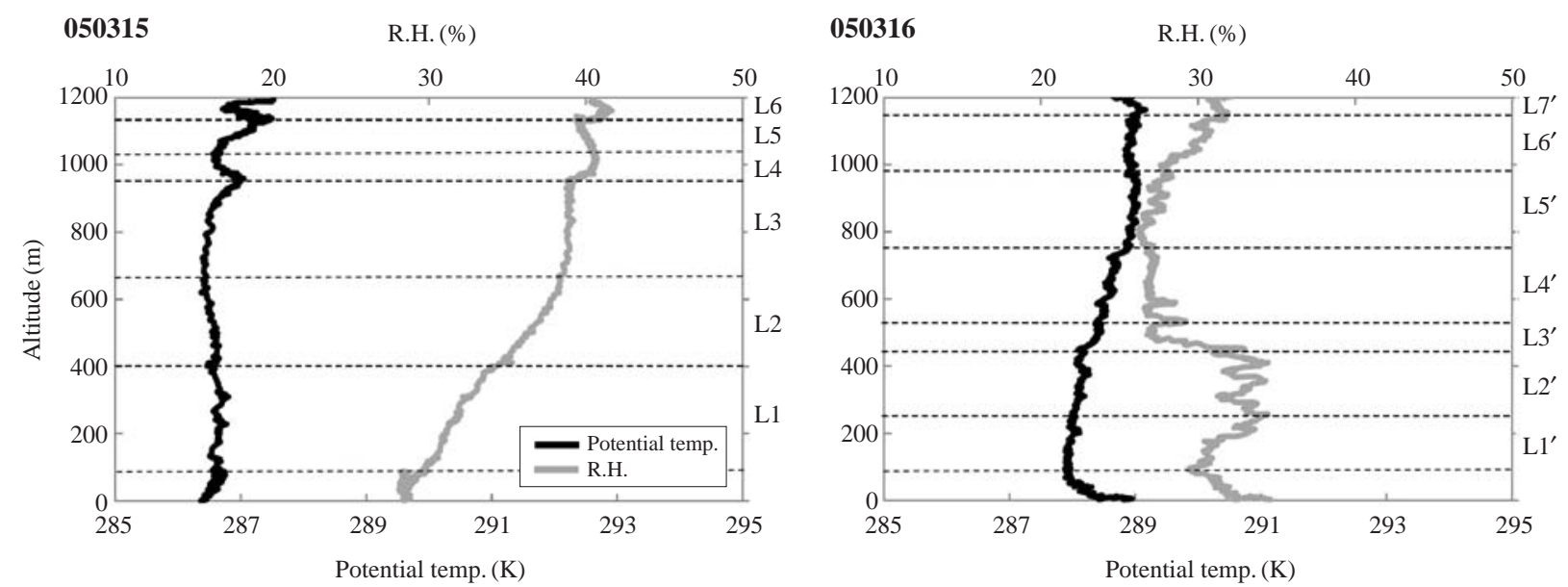

Fig. 3. Potential temperature (K) and relative humidity (R.H., \%) plotted separately for the two observation days (Left: March 15, right: March 16). The black lines represent the potential temperature and the gray lines represent the relative humidity. 

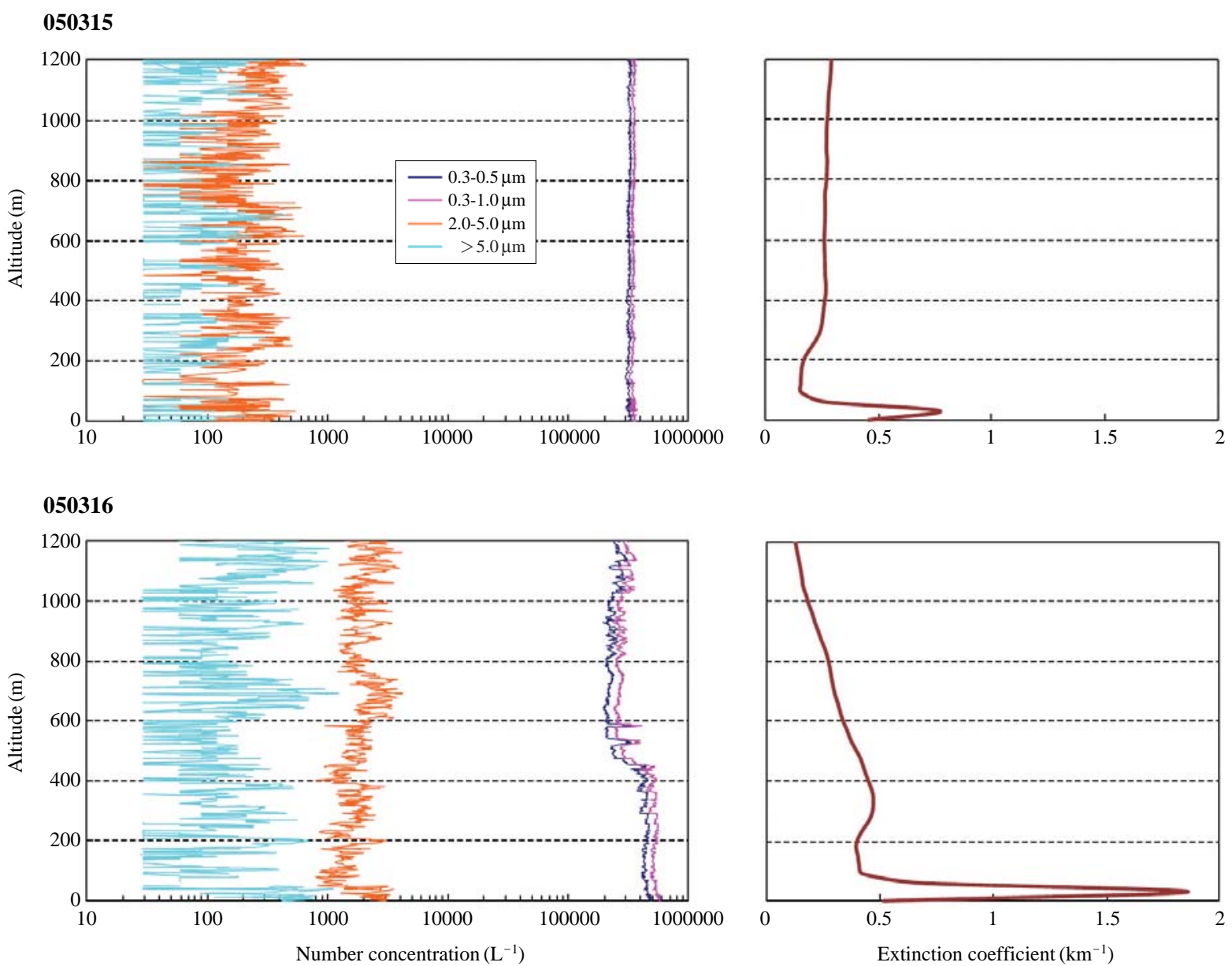

Fig. 4. Profiles of particle number concentrations $\left(\mathrm{L}^{-1}\right)$ in different size ranges and extinction ratio (km $\left.{ }^{-1}\right)$ on $\mathrm{March} 15$ (up) and 16 (down).

sorption properties in visible light wavelength ranges. Previous research has verified that the contribution of particulate aerosols to the extinction occupies more than $90 \%$ of the total $b$ over Beijing (Liu et al., 2004). Hence it is easily confirmed that the empirically determined equation (1) is roughly satisfied in the atmosphere over Beijing, and the visibility has approximately inverse correlation with the particle extinction. According to previous investigations, the size distributions and chemical compositions of atmospheric aerosols have been strongly affected by dust particles and particles of anthropogenic origin in the Beijing region (Wu et al., 2009; Li et al., 2008; Xu et al., 2008; Yuan et al., 2007; Wang et al., 2000; Liu et al., 1999). It is therefore interesting to analyse the relationship between extinction and the size-segregated number concentration of particles, in a case study of a large city in a developing country. However, this relationship cannot reveal which particle size controls the extinction.

\section{2 Vertical Structures of Particle Number Concentrations and Extinctions}

As described above, the distance between the lidar observation and balloon sounding sites is about 10 $\mathrm{km}$. Balloon-borne observations took about 1 hour to collect one dataset covering from near the ground to $1,200 \mathrm{~m}$. Horizontal scale of observation field (duration time of observation $\times$ typical wind speed) is considered to be about 7-10 km taking into horizontal wind speed of 2-3 m/sec during the observation. Hence the difference in the observation locations in the present analysis is negligible. As shown in Table 1, the weather conditions of the two observing days $(050315$ and 050316 represent March 15, 2005 and March 16, 2005 , respectively) were quite different: the former was a fine day, while the latter was more polluted, as shown by the weather report of the China Meteorological Administration. Figs. 3 and 4 present the vertical profiles of atmospheric relative humidity, potential temperature, size-segregated particle number concen- 

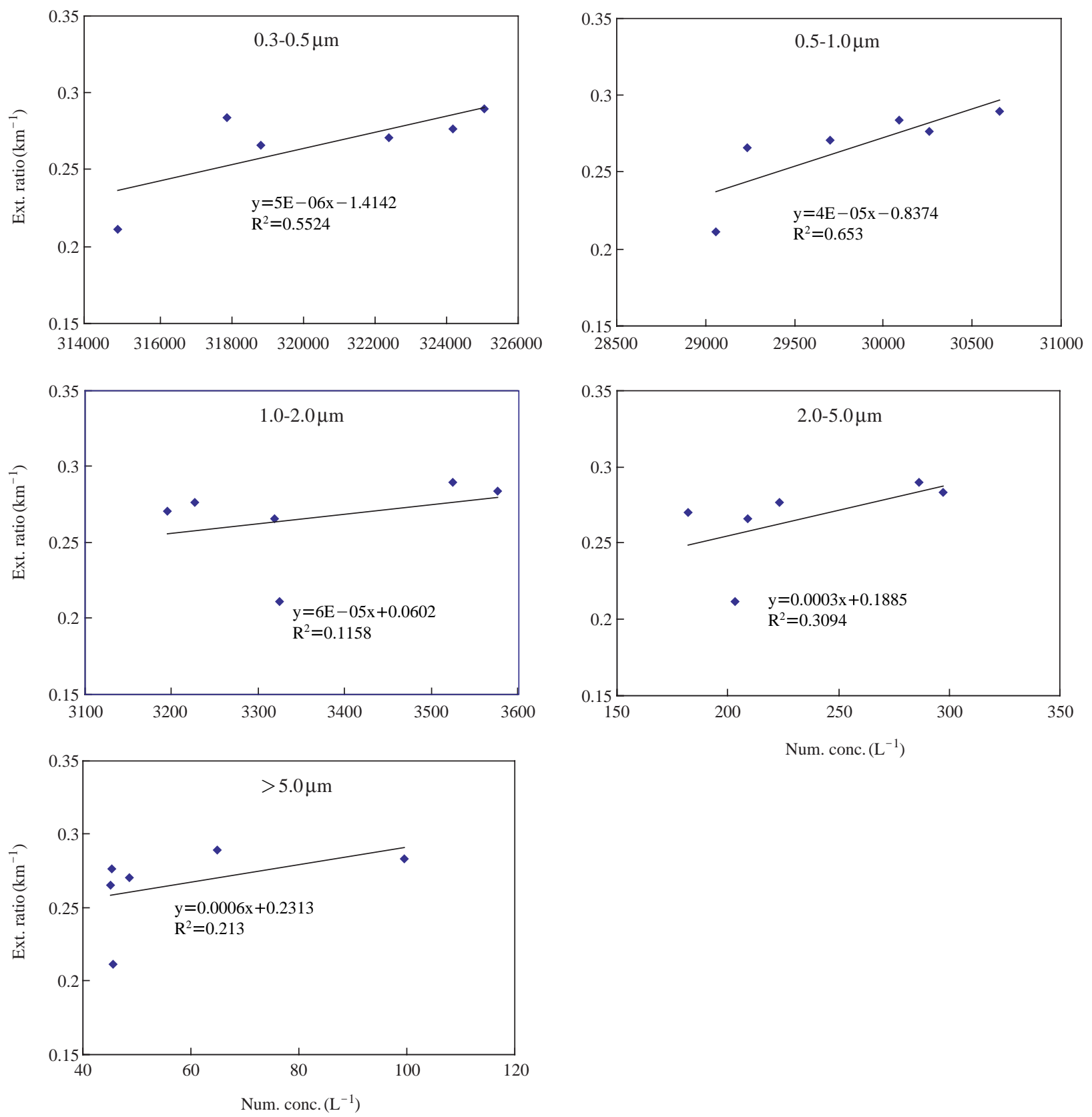

Fig. 5. Correlation between the extinction coefficients $\left(\mathrm{km}^{-1}\right)$ and the particle number concentrations $\left(\mathrm{L}^{-1}\right)$ in different size ranges in the case of 050315 (clear day).

tration, and light extinction for the respective days.

Comparing the particle concentration of March 15 with that of March 16 (Fig. 4), there is large difference in concentrations of particles with diameter $>2.0 \mu \mathrm{m}$, and values of March 16(dusty day) are about 10 times higher than those of March 15 (clear day) from near the ground to about $1,200 \mathrm{~m}$ height. From the profiles of coarse mode particle contents, it is suggested that the dust storm disturbed aerosols not only in the boundary mixing layer (potential temperature shows clear decline slope from the ground to about $80 \mathrm{~m}$ and narrow decline region at about $400 \mathrm{~m}$. Here we define the region from near the ground to $400 \mathrm{~m}$ as the boundary mixing layer of March 16) but also in the free atmosphere (Figs. 3 and 4). In the free atmosphere of March 16, relatively dry air was observed suggesting 

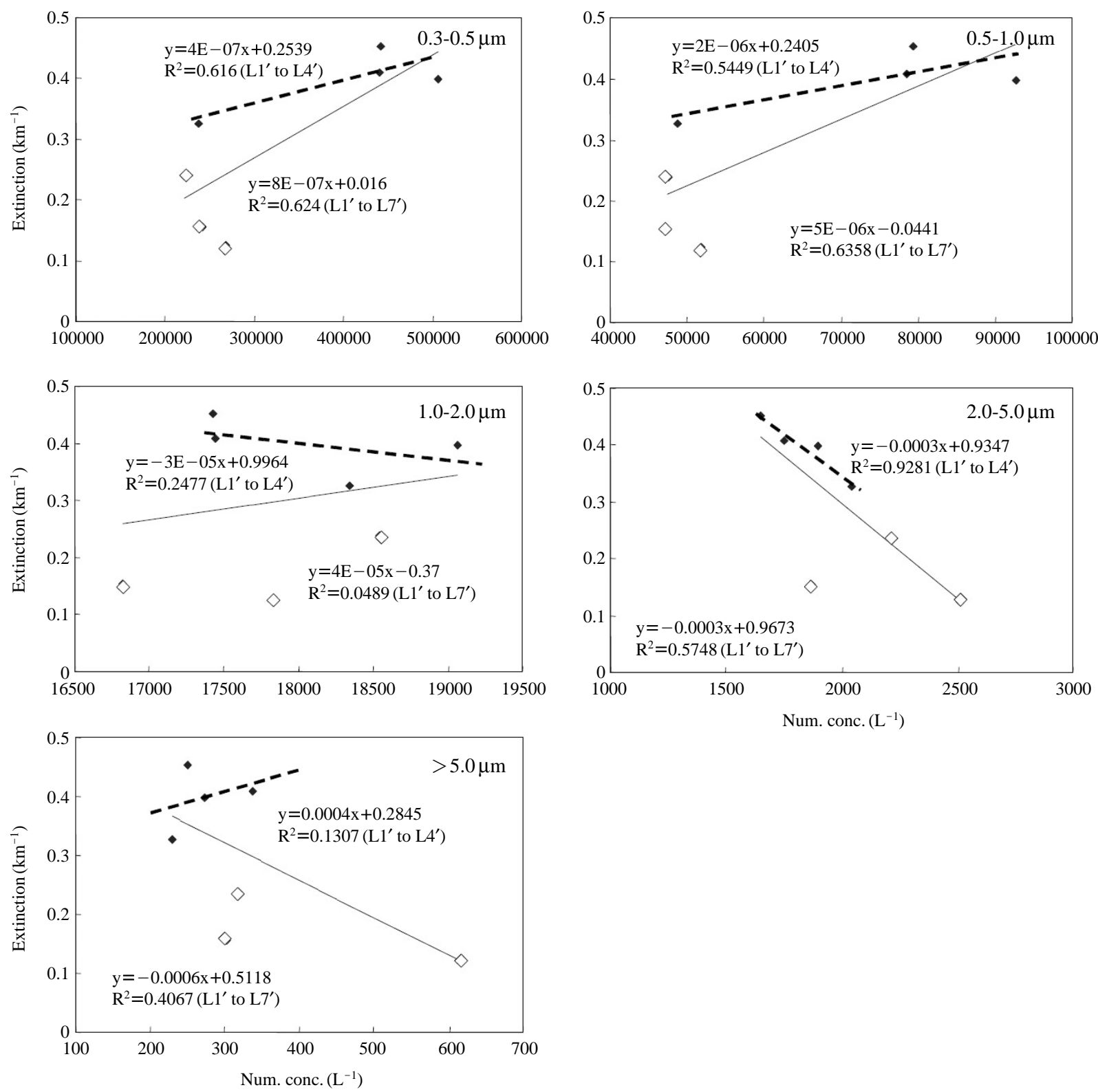

Fig. 6. Correlation between extinction coefficients $\left(\mathrm{km}^{-1}\right)$ and particle number concentration $\left(\mathrm{L}^{-1}\right)$ in each size range in the case of 050316 (dusty day). The dotted lines ( $\mathrm{L1}^{\prime}$ to $\mathrm{L4}^{\prime}$ ) show the correlation between the extinction and number concentration, neglecting data points $\mathrm{L}^{\prime}, \mathrm{L} 6^{\prime}$ and $\mathrm{L} 7^{\prime}$.

inclusion of air mass having different origins and/or histories (L4' and L5' in Fig. 3). Interestingly, extremely enhanced content of coarse mode particles was found in the dry air mass (Fig. 4).

Concerning with the concentration of fine particles, very interesting feature was observed in the dusty day (March 16) (Fig. 4). The fine particle concentration decreased in the free atmosphere (corresponding to the layers of $\mathrm{L}^{\prime}$ and $\mathrm{L} 5^{\prime}$ ), which were apparently lower than the level of the clear day (March 15). The decrease of the fine particle concentration has been, on the basis of ground-based particle sampling, frequently reported during dust episode by many investigators (e.g., Zhang et al., 2008). When the air mass such as the case in the free troposphere of 16 March descends to near the ground, high concentration of dust particles is observed without effect of pollutants including fine particles formed secondly from polluted gases.

The profile of potential temperature on March 15 
suggests active vertical mixing compared to that of 16 March, especially from near the ground to about $800 \mathrm{~m}$ height. It can be suggested that the stable thermodynamic structure of 16 March, especially from near the ground to about $80 \mathrm{~m}$, caused polluted air because the pollutants could not diffuse upwards and their concentrations became higher in the low atmosphere. Here, considering vertical profiles of potential temperature and relative humidity, we divided the boundary layer into six sub-layers (L1-L6) for 050315 and seven sub-layers (L1'-L7') for 050316 measurements. If we decide the boundary layer according to the position of the first clear inversion in the profiles of potential temperature, the boundary layer height will be about $150 \mathrm{~m}$ on March 15 and about $200 \mathrm{~m}$ on March 16 (Fig. 3). However, it is reasonable to determine the height of the boundary layer top considering humidity profiles in addition to the potential temperature profiles since the ground is large source of water vapour, and heights of about $950 \mathrm{~m}$ or $1,150 \mathrm{~m}$ of March 15 and about $430 \mathrm{~m}$ of March 16 would be top of the boundary layer (Fig. 3).

Fig. 4 shows the relation of the vertical profiles between the particle number concentrations in different size ranges and light extinction at the wavelength of $532 \mathrm{~nm}$. The extinction $\left(\alpha_{s l}\right)$ and particle number concentration $\left(C_{s l}\right)$ in each sub-layer are given by

$$
\alpha_{s l}=\frac{\int_{\delta z} \alpha(z, r) d z}{L_{s l}}
$$

and

$$
C_{s l}=\frac{\int_{\delta z} C(z, r) d z}{L_{s l}}
$$

where $\alpha(z, r)$ and $C(z, r)$ are extinction coefficient and particle number concentration as a function of altitudes $(z)$ in each sub-layer, respectively. $L_{s l}$ represents the layer thickness in each sub-layer (=layer top height-layer bottom height), respectively.

\section{3 Correlation between the Extinction and Particle Number Concentration}

Figs. 5 and 6 show the correlation between the extinction coefficients and the particle number concentrations in different size ranges in the case of 050315 (the clear day) and 050316 (the dusty day), respectively. According to (2) and (3), six data points of particle concentration and extinction were obtained for the clear day (Fig. 5) and seven data points were obtained for the dusty day (Fig. 6). Close positive correlations existed between the extinction coefficients and the particle number concentrations for particle diameters smaller than $1.0 \mu \mathrm{m}$ in both cases.

For particles of diameter larger than $2.0 \mu \mathrm{m}(050316$ case), assessing their contribution is difficult using only lidar data(Fig. 6) because the intensity of the laser beam possibly decreased as the laser beam penetrated the layer of large optical depth. Therefore the extinction deduced from the lidar measurements will be underestimated above about $800 \mathrm{~m}$, comparing the profiles of lidar returns of 050315 and 050316 in Fig. 4. The open symbols in Fig. 6 represent values that were considered to be disturbed by the large optical depth layer (L5', L6', and L7'). The correlation between fine-mode particle concentration and extinction is clearly positive even if the values higher than $800 \mathrm{~m}$ are neglected. However, correlation between coarsemode particle concentration and extinction is still negative even though the values of $\mathrm{L}^{\prime}, \mathrm{L}^{\prime}{ }^{\prime}$ and $\mathrm{L}^{\prime}$ are neglected, and effect of laser beam attenuation is not completely avoided.

Our results suggest that the contribution of finemode particles (diameter smaller than $1.0 \mu \mathrm{m}$ ) to light extinction or the visibility is important not only near the ground, but also over the planetary boundary layer (or the free troposphere) in Beijing. The attenuation of lidar beam is caused in dusty atmosphere, and consequently large underestimation of extinction is made. This is important problem to be solved when we want to estimate slant visibility from lidar return. To clarify this problem technically, future in situ measurements such as balloon-born OPCs are suggested. Here, we estimated extinction only at wavelength of $532 \mathrm{~nm}$. Observations at other wavelengths would also be useful to discuss the relation between extinction and aerosol concentration.

\section{SUMMARY}

We performed tethered-balloon observations twice in spring (on dusty and clear days) in Beijing, China. Vertical profiles of size-segregated particle concentration were obtained with the OPC. To understand the relationship between the visibility and the particulate matter suspended in the urban atmosphere, the vertical profiles of the OPC datasets and the corresponding lidar data were compared. The present observations reveal that the concentration of fine-mode particles (diameter $<1.0 \mu \mathrm{m}$ ) was positively correlated with the extinction. Consequently, fine-mode particles strongly contribute to light extinction and visibility in the boundary layer over Beijing, even under different weather conditions. However, the extinction deduced from the lidar return is certainly underestimated under the dusty atmospheric condition and correspondence 
between particle concentration and extinction is strongly disturbed, especially in size ranges of coarse particles due to strong lidar return attenuation.

The balloon-borne measurements showed that the aerosol layer was composed of some sub-layers. The sub-layers sometimes contained apparently higher content of particles than the value near the ground in dusty day, and therefore it will be hard to estimate slant visibility only from the lidar return data since intensity of laser pulse rapidly decreases during penetration in such high concentration particle layer. In situ measurements will be effective to correct underestimation in lidar return intensity, and the results presented here are only case study and much more observations are desired in future.

\section{ACKNOWLEDGEMENTS}

The work was supported by China's 973 Plan 2006CB403705 and The Ministry of Science and Technology of China (MOST) project 2009DFA2265. The authors are thankful to Dr. A. Shimizu and Dr. N. Sugimoto for preparing and processing the lidar data.

\section{REFERENCES}

An, J., Zhang, R., Han, Z. (2000) Seasonal changes of total suspended particles in the air of 15 big cities in northern parts of China. Climatic Environment Research 5(1), 25-29. (in Chinese)

Baik, N., Kim, Y.P., Moon, K.C. (1996) Visibility study in Seoul, 1993. Atmospheric Environment 30, 23192328.

Chan, Y.C., Simpson, R.W., Mctainsh, G.H., Vowles, P.D., Cohen, D.D., Bailey, G.M. (1997) Characterization of chemical species in $\mathrm{PM}_{2.5}$ and $\mathrm{PM}_{10}$ aerosols in Brisbane, Australia. Atmospheric Environment 31, 37733785.

Chan, Y.C., Simpson, R.W., Mctainsh, G.H., Vowles, P.D., Cohen, D.D., Bailey, G.M. (1999) Source apportionment of visibility degradation problems in Brisbane (Australia) using the multiple linear regression techniques. Atmospheric Environment 33, 3237-3250.

Charlson, R.J., Schwartz, S.E., Hales, J.M., Cess, R.D., Coakley, J.A., Hansen, J.E., Hofmann, D.J. (1992) Climate forcing by anthropogenic aerosols. Science 255, 423-430.

Dockery, D.W., Pope, C.I. (1994) Acute respiratory effects of particulate air Pollution. Annual Review of Public Health 15, 107-132.

Donaldson, K., Li, X.Y., MacNee, W. (1998) Ultra-fine (nanometer) particle mediated lung injury. Journal of Aerosol Science 29, 553-560.

Hayashi, M., Iwasaka, Y., Watanabe, M., Shibata, T.,
Fujiwara, M., Adachi, H., Sakai, T., Nagatani, M., Gernandt, H., Neuber, R., Tsuchiya, M. (1998) Size and number concentration of liquid PSCs: Balloonborne measurements at Ny-Ålesund, Norway in winter of 1994/95. Journal of the Meteorological Society of Japan 76, 549-560.

Jacobson, M.Z. (2001) Global direct radiative forcing due to multicomponent anthropogenic and natural aerosols. Journal of Geophysical Research 106, 1551-1568.

Koschmieder, H. (1924) Theorie der horizontalen Sichtwcete, Bcetr. Physical Atmosphere 12, 33-53.

Larson, S.M., Cass, G.R. (1989) Characteristics of summer middy low visibility events in the Los Angeles area. Environmental Science \& Technology 23, 281.

Li, B.G., Ran, Y., Tao, S. (2008) Seasonal variation and spatial distribution of atmospheric aerosols in Beijing. Acta Scientiae Circumstantiae 28(7), 1425-1429. (in Chinese)

Liu, X., Shao, M. (2004) The analysis of sources of ambient light extinction coefficient in summer time of Beijing city. Acta Scientiae Circumstantiae 24(2), 185189. (in Chinese)

Liu, Y., Zhou, M. (1999) The internal variation of mineral aerosols in the surface air over Beijing and the East China Sea. Acta Scientiae Circumstantiae 19(06), 642647. (in Chinese)

Matsuki, A., Iwasaka, Y., Shi, G.-Y., Chen, H.-B., Osada, K., Zhang, D., Kido, M., Inomata, Y., Kim, Y.-S., Trochkine, D., Nishita, C., Yamada, M., Nagatani, T., Nagatani, M., Nakata, H. (2005) Heterogeneous sulfate formation on dust surface and its dependence on mineralogy: balloon-borne observations from balloon-borne measurements in the surface atmosphere of Beijing, China. Water, Air, \& Soil Pollution: Focus 5(3-6), 101132.

Peundorf, R. (1957) Tables of the refractive index for standard and the Rayleigh scattering coefficient for the spectral region between 0.2 and $20.0 \mu$ s and their application to atmospheric optics. Journal of the Optical Society of America 47, 176-182.

Prospero, J.M. (1999) Long range transport of mineral dust in the global atmosphere: Impact of African dust on the environment of the southeastern United States. Proceedings of the National Academy of Sciences USA 96, 3396-3403.

Seinfeld, J.H., Pandis, S.N. (1998) Atmospheric Chemistry and Physics: From Air Pollution to Climate Change (John Wiley, New York), pp. 724-743.

Shimizu, A., Sugimoto, N., Matsui, I., Arao, K., Uno, I., Murayama, T., Kagawa, N., Aoki, K., Uchiyama, A., Yamazaki, A. (2004) Continuous observations of Asian dust and other aerosols by polarization lidars in China and Japan during ACE-Asia. Journal of Geophysical Research 109, D19S17, doi:10.1029/2002JD003253.

Song, Y., Tang, X.Y., Fang, C., Zhang, Y.H., Hu, M., Zeng, L.M., Li, C.C., Mao. J.T. (2003) Relationship between the visibility degradation and particle pollution in Beijing. Acta Scientiae Circumstantiae 23(4), 468- 
471. (in Chinese)

Sugimoto, N., Uno, I., Nishikawa, M., Shimizu, A., Matsui, I., Dong, X.H., Chen, Y., Quan, H. (2003) Record heavy Asian dust in Beijing in 2002: Observations and model analysis of recent events. Geophysical Research Letters 30(12), 1640, doi:10.1029/2002GL016349.

Wang, J.L., Liu, X.L. (2006) The discuss on relationship between visibility and mass concentration of $\mathrm{PM}_{2.5}$ in Beijing. Acta Meteorologica Sinica 64(2), 221-228. (in Chinese)

Wang, W., Tang, D., Liu, H., Yue, X., Pan, Z., Ding, Y. (2000) Research on current pollution status and pollution characteristics of $\mathrm{PM}_{2.5}$ in China. Research of Environmental Sciences 13(1), 1-5.

Wu, M., Niu, Z., Qiao, Y., Wu, C. (2009) Aerosol types and its affecting factors over Beijing: Based on MODIS data. GEO-INFORMATION SCIENCE 11(4), 541548. (in Chinese)

Xu, J., Zhang, X., Yan, P., Ding, G., Xu, X. (2008) Observational study of aerosol extinction property during dust weather in background area. Meteorological Science and Technology 36(6), 679-685. (in Chinese)

Yamashita, K., Hayashi, M., Irie, M., Yamamoto, K., Saga, K., Ashida, M., Shiraishi, K., Okabe, K. (2005)
Amount and state of mineral particles in the upper mixed layer and the lower free troposphere over Mt. Raizan, southwestern Japan: unmanned airplane measurements in the Spring of 2003. Journal of the Meteorological Society of Japan 83A, 121-136.

Yan, F.Q., Hu, H.L., Zhou, J. (2003) Measurement of number density distribution and imaginary part of refractive index of aerosol particles. Acta Optica Sinia 23(7), 855-859. (in Chinese)

Yuan, Y., Liu, D., Che, R., Dong, X. (2007) Research on the pollution situation of atmospheric particulates during Autumn in Beijing city. Ecology and Environment 16(1), 18-25. (in Chinese)

Zhang, R., Xu, Y., Han, Z. (2003) Inorganic chemical composition and source signature of $\mathrm{PM}_{2.5}$ in Beijing during ACE2 Asia period. Chinese Science Bulletin 48(7), 730-733. (in Chinese)

Zhang, R., Han, Z., Shen, Z., Cao, J. (2008) Concentrations and elemental composition of aerosol particles for a dust storm event in Beijing, Advances in Atmospheric Sciences (25), 89-95.

(Received 26 May 2010, accepted 23 July 2010) 